\title{
Evaluation of Antitumor and Antioxidant Activity of Sargassum tenerrimum against Ehrlich Ascites Carcinoma in Mice
}

\author{
Satyajit Patra ${ }^{1 \& *}$, Meenakshi Sundaram Muthuraman ${ }^{2 \& *}$, ATJ Ram Prabhu ${ }^{3}$, \\ R Ramya Priyadharshini², Sujitha Parthiban ${ }^{2}$
}

\begin{abstract}
Context: In the last half century, discovering, developing and introducing of clinical agents from marine sources have seen great successes, with examples including the anti-cancer compound trabectedin. However, with increasing need for new anticancer drugs, further exploration for novel compounds from marine organism sources is strongly justified. Objective: The major aim of this study was to evaluate the antitumor and antioxidant potential of Sargassum tenerrimum J.Agardh (Sargassaceae) on Ehrlich ascites carcinoma (EAC) in Swiss albino mice. Materials and Methods: An ethanol extract of S. tenerrimum (EEST) from whole algae was used to evaluate cytotoxicity followed by in vivo assessment of toxicity, using biochemical parameters including hepatic and non-hepatic enzymes. Antioxidant properties were examined in animals bearing EAC treated with daily oral administration of 100-300 mg/kg extract suspension. Results: Antitumor effects of EEST in EAC bearing mice was observed with LD50 $1815 \mathrm{mg} / \mathrm{kg}$. Parameters like body weight, tumor volume, packed cell volume, tumor cell count, mean survival time and increase in life span in animals in the EAC bearing animals treated with EEST $300 \mathrm{mg} / \mathrm{kg}$ was comparable with control group. Significant differences were also seen with changes in total protein content, hepatic enzymes contents, MDA level, and free radical scavenging enzymes in untreated vs. EEST treated group animals. Conclusions: Evaluation of antioxidant enzymes and hepatic enzymes in the EAC animal model treated with EEST exhibited similar effects as the positive control drug 5-flurouracil. $S$. tenerrimum extracts contain effective antioxidants with significant antitumor activity.
\end{abstract}

Keywords: Algae ethanolic extract - cytotoxic activity - survival time - hepatic enzymes - lipid peroxidation

Asian Pac J Cancer Prev, 16 (3), 915-921

\section{Introduction}

Cancer is a devastating disease with tremendous negative implications at the personal, health care, economical and social levels. About 14.1 million cancer cases were diagnosed around the world in 2012, of these $52.5 \%$ were in men and $47.5 \%$ in women, and is expected to rise up to 21.7 million by 2030 . This disease contributed to total 8.2 million deaths worldwide in 2012 and expected to increase to 13.0 million by the end of 2030 (Burney et al., 2014). A majority of the deaths associated with cancer occur in low- and middle-income countries with limited access to medical resources and health systems (Miranda et al., 2008). The search for an effective cure for cancer continues to improve survival of cancer patients (Tohme et al., 2011). The Ehrlich tumor was initially described as a spontaneous murine mammary adenocarcinoma (Dolai et al., 2012) with the ability to grow in almost all strains of mice as a rapidly growing carcinoma and very aggressive behavior (Calixto-Campos et al., 2013). The advantage of use of Ehrlich tumor as tumor model includes the property of transplantable tumor model in the ascites form to evaluate antitumor activities of various natural and synthetic drugs (Haldar et al., 2010).

The proposed natural drug in this study is Sargassum tenerrimum J.Agardh (Sargassaceae), which is generally planktonic macro alga (seaweed) (Sharma, 1986). Sargassum grows in from just below the low-water mark to a depth of $10 \mathrm{~m}$ and these species are found throughout tropical areas of the world, commonly used as a good source for production of sodium alginate, animal feed, fertilizer, and medicine. Average yield of mannitol from S. tenerrimum is $9 \%$. Sargassum species are demonstrated as potential natural pharmacological source for different health benefits including activities like analgesic, antiinflammatory, antioxidant, neuroprotective, antimicrobial, antitumor, fibrinolytic, immune-modulatory, anticoagulant, hepatoprotective, antiviral activities (Yende et al., 2014). Sargassum algae extract are reported to be inhibiting tumor cell replication in an in vitro model (Zandi et al., 2010), where as other studies indicating polysaccharides isolated form Sargassum algae showed significant anti-

${ }^{1}$ Division of Biochemistry and Genetics, American International Medical University, Saint Lucia, ${ }^{2}$ Department of Biotechnology, School of Chemical and Biotechnology, SASTRA University, Thanjavur, ${ }^{3}$ Department of Biotechnology, Srimad Andavan Arts \& Science College, Trichy, Tamil Nadu, India ¿Equal contributors*For correspondence: satyajitpatra@gmail.com, msundar77@gmail.com 
tumor activity both in vitro and in vivo (Ye et al., 2008), and improved the immune function in tumor-bearing mice (Chen et al., 2012). It is also suggested that the Sargassum algae extract competently increase the apoptotic-induced cytotoxicity against epithelial mammary gland and colorectal adenocarcinoma cells (Khanavi et al., 2010). We hypothesize that; with the antioxidant property of $S$. tenerrimum this alga may exhibit significant anticancer property. This study was focused to evaluate the anticancer activity of the alga $S$. tenerrimum in an in vivo model of EAC bearing mice.

\section{Materials and Methods}

\section{Collection of plant material and preparation of plant extract}

Fresh algae of $S$. tenerrimum were collected during December (2009) from the Mandapam region, Tamil $\mathrm{Nadu}$, India. No specific permission was required for the collection of these algae as these were collected from regional seashore, not covered by any regulatory body and private land. The alga sample collected was matched with the herbarium voucher specimen of $S$. tenerrimum (ALII-114-03) available at CSMCRI Herbarium, India. The alga was shade dried and coarsely powdered and processed for extract preparation and identification of active constituents as reported in our previous studies (Patra and Muthuraman, 2013). Preliminary observation (data not shown) suggested effective activities by the ethanol extract, and henceforth ethanol extract of Sargassum tenerrimum (EEST) was used in this study for evaluation of antitumor activity. The ethanol extract was filtered, and the solvent was removed under vacuum, using a rotary evaporator. The EEST extract was suspended in a $0.5 \%$ carboxymethylcellulose solution and was administered by oral gavage once per day. Mice in control group were given the $0.5 \%$ carboxymethylcellulose solution (vehicle control) only. The body weights of individual rats were monitored weekly.

\section{Animals}

Adult Swiss albino mice weighing between 25-30 g were procured from Tamilnadu Veterinary and Animal Science University, Chennai. The animals had free access to food and tap water during the acclimatization and experimental periods and were exposed to $12 \mathrm{~h}$ of light/ dark cycle during the study. The study was conducted after obtaining necessary Animal Ethical Committee clearance (Reg.No:790/03/ac/CPCSEA).

\section{Experimental design and drug treatment schedule}

The mice were divided into 6 groups of twelve animals each as, group-1 - normal control, group-2: disease controls, group-3-5 were treated daily with EEST at dose of $100,200,300 \mathrm{mg} / \mathrm{kg}$ respectively and animals in group-6 received 5-Flurouracil $(20 \mathrm{mg} / \mathrm{kg}$ ) (Goto et al., 2004). The experiment was started by inoculating EAC cell line $\left(2 \times 10^{6}\right.$ cells/mouse $)$ to all the animals in group 2-6 and after $24 \mathrm{~h}$ animals in the group 1-2 received vehicle control, animals in the group 3-5 were treated with EEST, and animals in the group-6 were treated with the 5-Florouracil and animals were administered daily with drugs/vehicle by oral route. On day 14 , after administration of last dose followed by $18 \mathrm{~h}$ fasting, six mice form each groups were sacrificed for the study of anticancer activity, hematological, and liver biochemical parameters. Liver was dissected out, homogenized and used for the antioxidant studies. The remaining animals in each of the groups were kept to check the mean survival lime (MST) and percent increase in life span (\%ILS) of the tumor-bearing hosts. Various parameters such as body weight of animals, life span of animals, cytological studies of cell lines, hematological parameters, RBC, WBC, hemoglobin, differential count, and biochemical parameters were evaluated in this study. Anticancer effect of EEST was assayed by observation of change with respect to body weight, ascitic tumor volume, packed cell volume, viable and nonviable tumor cell count, MST, and $\%$ ILS.

\section{Cells}

EAC cell lines were provided by courtesy of Amala Cancer Research Center, Thrissur, India. They were maintained by weekly intraperitoneal inoculation of $10^{6}$ cells/mouse (Gothoskar and Ranadive, 1971).

\section{Toxicity evaluation (LD50) and dose selection}

Acute toxicity study was conducted in animals after acclimatization to laboratory conditions, animals were divided into 6 groups of 6 mice each with access to free food and water ad libidum. The control received vehicle control used, while the experimental groups received EEST orally at different doses of 500, 1750, 2000, 2500 and $3000 \mathrm{mg} / \mathrm{kg}$ for 40 days and observed for signs of toxicity like behavioral changes, increased respiratory rate, nervous imbalance and death. The toxicological effects were observed in terms of mortality expressed as LD50 (Jung and Choi, 1994). Based on the experimental observations, the acute oral LD50 of the extract was calculated by the use of software for probit analysis (Environmental Protection Agency Probit Analysis Program, used for calculating LC/EC value, Version 1.5).

\section{In vitro cytotoxicity}

The tumor cells were used to study the cytotoxicity of EEST after aspirating from the peritoneal cavity of tumor bearing mice. Cells were divided into 4 tubes, and were mixed with EEST at $0,25,50,100 \mu \mathrm{g} / \mathrm{ml}$ concentration respectively and incubated at $37^{\circ} \mathrm{C}$ for $3 \mathrm{~h}$ for cytotoxic activity. After incubation, $1 \%$ tryphan blue dye in isotonic saline was added to each tube and viability was evaluated by calculating the ratio of viable (unstained) and dead (stained) cells. The cytotoxicity was calculated as number of viable cells over number of total cells and was presented as percentage of cytotoxicity.

\section{Mean survival time and percent increased in life span}

Survival time for the animals treated with EEST and effect of EEST on tumor growth was observed by MST and \%ILS (Sur and Ganguly, 1994). MST of each group containing 6 mice was monitored by for 7 weeks and endpoint of experiments was determined by spontaneous 
death of animals to calculate \% ILS using GrpahPad software.

\section{Determination of biochemical markers, hepatic and antioxidant enzymes}

Blood sample collected from the experimental animals was used for the estimation of biochemical parameters including total cholesterol, uric acid, triglycerides, glucose and protein using automatic analyzer (Hitachi, Tokyo, Japan). To estimate the serum hepatic enzymes level in the experimental animals, serum was separated and the level of SGOT, SGPT, ALP and LDH were estimated by using commercial kit as per manufacturer's instruction (Span diagnosis Ltd, Surat, India). Antioxidant enzymes were evaluated in the liver tissue collected from the experimental animals after excision and immersion in ice-cold saline. After rinsing twice in buffer, the liver was weighed and homogenized with a Teflon potterElvehjem homogenizer in measured volumes of Phosphate buffer ( $\mathrm{pH}$ 7.4). The homogenate was then centrifuged at $10,000 \mathrm{rpm}$ for $10 \mathrm{~min}$. The supernatant was used for the investigation of the level of super oxide dismutase (SOD), lipid peroxide (LPO), reduced glutathione and catalase (Mohun and Cook, 1957; Misra and Fridovich, 1972; Sinha, 1972; Moron et al., 1979; Ohkawa et al., 1979).

\section{Statistical analysis}

All in vitro experiments were performed in triplicate and results are represented as means \pm SD. ANOVA followed by Tukey test was performed in this study to evaluate the significant differences among groups. The acute toxicity of mice was demonstrated using the Kaplan-Meier method and the logrank (Cox-Mantel) statistical test was applied to compare the curves for nonparametric procedures. Values where $\mathrm{p}<0.05$, differences were considered significant at representing two-sided test of statistical significance.

\section{Results}

Phytochemical screenings of S. tenerrimum suggest that ethanolic extract of the algae contain alkaloids, flavonoids, steroids, glycosides, phenols and saponins which are believed to be the potential component for anticancer activity (Table 1) (Khan et al., 2012).

Table 1. Result of Phytoconstituent Identification Tests of $S$. Tenerrimum

\begin{tabular}{lccccc}
\hline Extract & PEST & CEST & ACEST & EEST & AEST \\
\hline Alkaloids & - & - & & + & - \\
Coumarin & - & - & - & - & - \\
Flavonoids & - & - & + & + & + \\
Glycosides & - & - & - & + & + \\
Mucilages & + & + & + & + & - \\
Phonols & - & - & - & + & - \\
Phytosterols & - & - & - & + & - \\
Quinones & - & - & - & - & - \\
Saponins & - & - & - & + & - \\
Triterpenoid & - & - & - & - & - \\
\hline
\end{tabular}

*Negative (-) absent, Positive (+) present; PEST = Petroleum ether extract; CEST: Chloroform extract; ACEST: Acetone extract; EEST: Ethanolic extract; AEST: Aqueous extract
Toxicity evaluation (LD50) of EEST and effect on survival time

In acute toxicity study for extract of S. tenerrimum, the alga was evaluated for mortality in the animals treated with highest dose up to $3000 \mathrm{mg} / \mathrm{kg}$ (Figure 1). The LD50 was calculated to be $1815 \mathrm{mg} / \mathrm{kg}$ and safe dose was determined by organization for economic cooperation and development (OECD) guidelines.

The extract shows sedation, hypnosis, and mild muscle relaxant property. Administration of EEST reduces the tumor volume, packed cell volume, and viable tumor cell count in a dose-dependent manner when compared to EAC control mice. In EAC control mice, the average survival time was $19 \pm 0.25$ days. Whereas, it was significant increased median survival time $(24 \pm 0.33,26 \pm 0.49$, $33 \pm 0.58)$ with different doses $(100,200$ and $300 \mathrm{mg} /$ $\mathrm{kg}$ ) of EEST and standard drug, respectively. The lowest concentration of the EEST had a significant $40 \%$ increase in mean survival time in comparison with tumor control and the intermediate concentration had 59\% increase. The highest concentration of EEST used had the better survival time $(84.7 \%)$ and was also very close to the standard control 5-flurouracil (5-FU) $(91.4 \%)$. MST and the effect of EEST $(100,200$ and $300 \mathrm{mg} / \mathrm{kg})$ at different doses on tumor volume, viable, and nonviable cell count were shown in Figures 2 and 3.

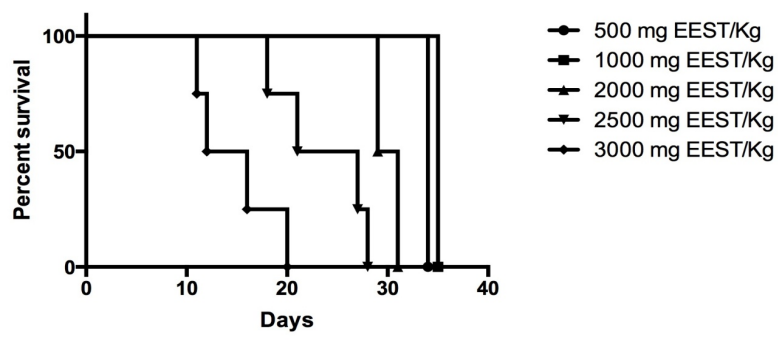

Figure 1. Toxicity Effect of EEST on Swiss Albino Mice after Administration of Different Concentration of EEST for Forty Days Exposure Period

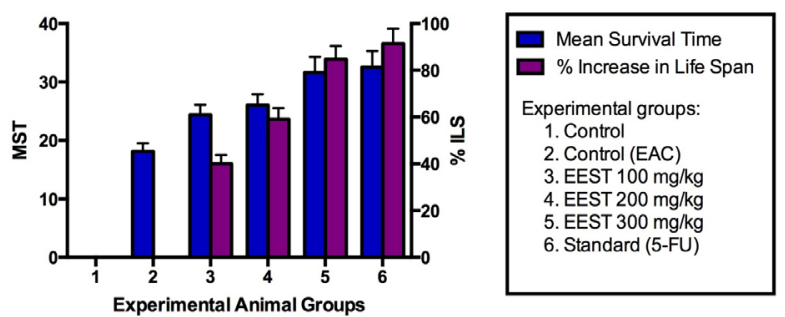

Figure 2. Effect of EEST on the Animals in Different Group for the Mean Survival Time and Percentage Increase in Life Span

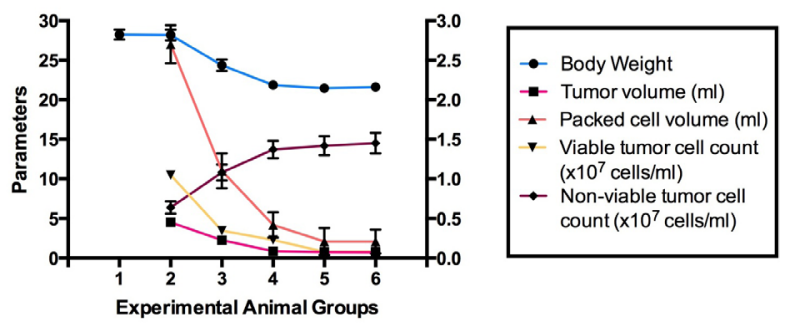

Figure 3. Graphical Representation of Effect of EEST on Various Parameters. 


\section{Cytotoxicity effect}

Cytotoxicity of EEST was done by standard in vitro method, where three different concentrations of the ethanolic extract of selected algae were used to evaluate the toxicity towards EAC. The lowest concentration of EEST $(25 \mu \mathrm{g} / \mathrm{ml})$ had significant effect on cell death as the percentage of viable cells was reduced to $50 \%$ compared to control group. With increase in concentration of EEST the percentage of viable cells further reduced indicating dose dependent response of EEST towards EAC cells. At $100 \mu \mathrm{g} / \mathrm{ml}$ concentration more than $80 \%$ cells were found to be dead (Figure 4).

\section{Effect of EEST on biochemical parameters}

The influence of EEST on the biochemical parameters like glucose, triglyceride, total protein and uric acid level

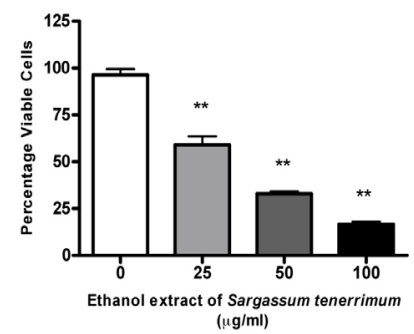

Figure 4. Cytotoxicity Effect of EEST. Evaluated by counting viable cells using dye exclusion method and compared
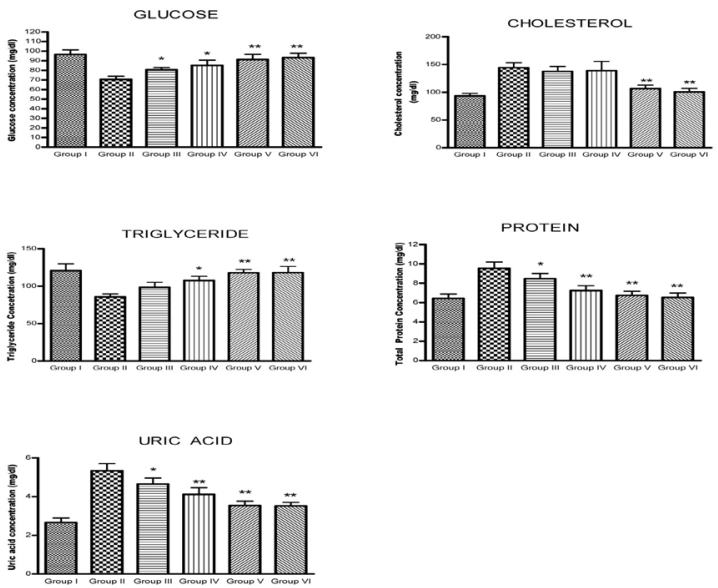

Figure 5. Effect of EEST on Biological Parameters. Changes in biological parameters like glucose, cholesterol, triglyceride, protein, uric acid levels in animals treated with EEST or 5-FU was compared with tumor control group. *p $<0.05$, $* * \mathrm{p}<0.01$
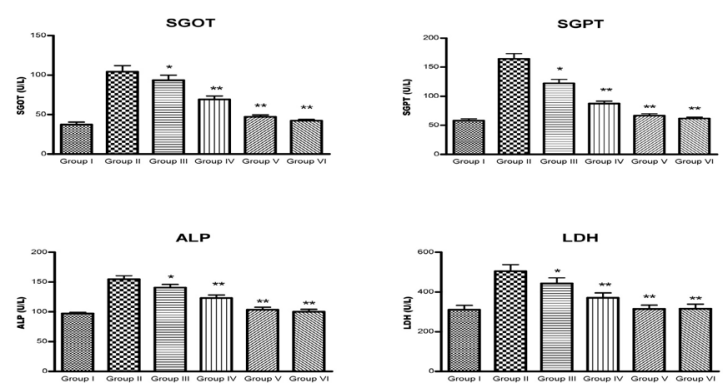

Figure 6. Effect of EEST on of hepatic and non-hepatic enzymes. Various hepatic and non-hepatic enzymes including SGOT, SGPT, ALT and LDH levels in EEST and 5-FU treated animals were evaluated and compared with tumor control group. $* \mathrm{p}<0.05, * * \mathrm{p}<0.01$ of EAC bearing and normal mice were carried out (Figure $5)$. Glucose concentration in the tumor bearing control mice (group-2) was found to be lowered compared to control group (group-1) and when animals were treated with EEST (300 mg/kg) (group-5) the glucose level came to close normal level and similar observations were noted in standard 5-FU drug. In tumor bearing mice the cholesterol level was comparatively higher than the normal group however in the animals in group- 5 treated with EEST $(300 \mathrm{mg} / \mathrm{kg})$, the cholesterol level dropped down to the level similar to control animal and similar effects was observed with 5-FU. At 100 and $200 \mathrm{mg}$ / $\mathrm{kg}$ of EEST the cholesterol was not significantly altered compared to the group-2 animal.

Triglycerides concentration level showed similar characteristic with cholesterol, found to be decreased in the tumor bearing mice compared to the control group. In treatment with EEST at both 100 and $200 \mathrm{mg}$ doses the triglyceride level increased and the $300 \mathrm{mg}$ treated group have significant effect on triglyceride by bringing the concentration back to normal as achieved by 5-FU. The total protein was found to be elevated in the tumor bearing mice and in treatment with EEST it was found the total protein concentration decreased to normal level as dose dependent manner. Uric acid was higher in the tumor bearing mice compared to the normal group of mice and it was found that the concentration of uric acid decreased to normal level in the animals treated with EEST. These biochemical parameters indicate that in treatment with EEST at $300 \mathrm{mg} / \mathrm{kg}$ the drug was able to show significant activity and was able to mimic the condition with normal animals as observed with standard drug.

\section{Effect of EEST on hepatic enzymes}

Level of hepatic enzymes in the serum is indicator state of the liver or biliary system integrity and in this study induced liver damage in EAC bearing and treated mice were estimated (Figure 6). Level of three major hepatic (SGOT, SGPT and ALP) and one non-hepatic enzyme $(\mathrm{LDH})$ were evaluated in this study to find out the effect of EEST. Marked elevation of these enzymes in liver tissue in the tumor bearing mice indicates damage to the tissue and administration of EEST to the animals bearing tumor was expected to reduce oxidative stress indicating its protective role in liver tissue. This study supported this hypothesis, where change in the activities of some liver
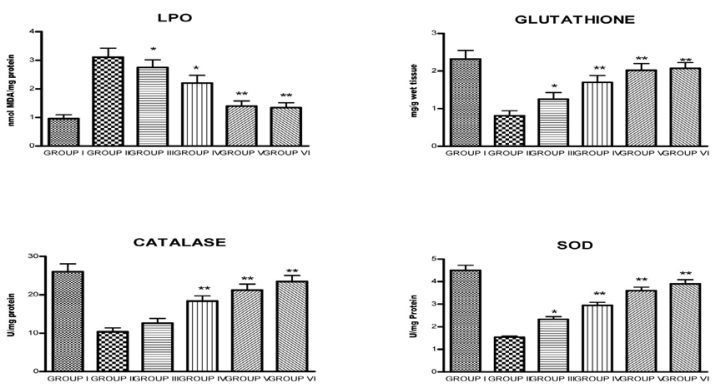

Figure 7. Effect of EEST on Antioxidant Substrate and Enzymes of EAC Bearing Animals. Enzymes associated with antioxidant activity were estimated in animals treated with EEST and 5-FU and the difference with disease control group was compared. $* \mathrm{p}<0.05, * * \mathrm{p}<0.01$ 
enzymes in tumor bearing mice was observed, and it may be associated with antioxidant property of EEST exhibited (Figure 7). Interestingly, when EEST was administered to tumor bearing mice, all elevated hepatic enzyme levels were dropped to a level comparable with control animals (group-1), supporting the antioxidant and hepatoprotective role of EEST.

\section{Effect of EEST on antioxidant enzymes}

The antioxidant potential of $S$. tenerrimum was evaluated by estimating parameters like super oxide dismutase (SOD), lipid peroxide (LPO), reduced glutathione, and catalase in the liver tissues of EAC bearing mice (Figure 7). LPO level was found to be highly elevated in the tumor bearing mice and treatment with EEST, the level of LPO decreased and it was in comparable with increased concentration of EEST. At 300 mg dose of EEST, the concentration of LPO showed no significant difference than control normal mice indicating the effect of EEST as antioxidant.

On the other hand, the concentration of glutathione in the tumor bearing mice was less than half in comparison with normal control. In treatment with EEST, the glutathione concentration reversed, however, with the two lower concentration of EEST the concentration was not significantly closer to normal control. But the highest concentration of EEST (300 mg) had a significant action on reversal of glutathione concentration to normal. Similar observations were also made with catalase and SOD. In both cases of catalase and SOD, the concentrations of these enzymes were lowered more than half in the tumor bearing control mice. When these mice were treated with EEST, the levels of these enzymes were observed to be elevated with EEST. At $300 \mathrm{mg}$ dose of EEST, the level of catalase was elevated but was not very close to the normal control as it was observed in the positive control drug 5-FU, however, the effect was concentration dependent. This drug EEST was comparatively better effective in reversing the condition of SOD. At the highest dose used in this study i.e., $300 \mathrm{mg}$ the concentration of the SOD in the body was no significantly different than normal control mice. In all the antioxidant enzymes evaluated in the study they were altered in the tumor bearing control mice. When these mice were treated with EEST at three different concentrations, the levels of these enzymes were found to be reaching normal control mice concentration as dependent of dose. In the entire enzymatic assay, the positive control drug used 5-FU was able to bring it to normal level. This indicates the effect of drug was based on the mechanism of antioxidant activities.

\section{Discussion}

This study is an example to illustrate the intense excitement which surrounds the achievements in the area of new anticancer leads from marine organisms in last two decades (Simmons et al., 2005), and remarkable successes in discovering, developing and introducing clinical agents derived from marine sources are continuously being reported (Desbois, 2014). Several marine-derived drugs have entered clinical trials for cancer therapy, but failed in different stages due to the lack of the expected therapeutic efficacy (Riely et al., 2007; Lu et al., 2010). In last few years, strategy for the screening and discovery of new anticancer leads from nature has been seen to evolve with novel approaches, and at same time screening strategies are continuing to evolve, probing new ideas and knowledge of cancer, introducing high modern screening techniques and new analytic methodologies (Dolma et al., 2003). In this study an attempt was made toward identification of novel anticancer drug and we carried out this research work to evaluate the antitumor effect and antioxidant status of S. tenerrimum on EAC-bearing mice. In earlier reports of the Sargassum species such as Sargassum wightii Greville (Sargassaceae) (Singaravelu et al., 2007), Sargassum polytricum (Sargassaceae) (Khanavi et al., 2010) have presented potential anticancer activity, it is suggestive that algae from this species have potential anticancer properties.

$S$. tenerrimum a marine alga is predominant in the coastal areas of Tamil Nadu and all around the world and was selected for further investigation for anticancer property based on our preliminary results from screening for chemical agents in Sagassum species. Ethanolic extract of this alga was selected based on the observation of presence of various phytochemical constituents including alkaloids, flavonoids, glycosides and sterols. These components have been reported extensively toward the explanation of various natural drugs for their anticancer activities (Brown et al., 1991; Lee, 1999; Ali et al., 2012), and hence ethanol extract was selected to evaluate the anticancer property of S.tenerrimum and was administered orally as a suspension and subjected to in vitro and in vivo studies.

Prolongation of life span and decrease in WBC has been the persistent criteria for judging the potency of any anticancer drug (El-Shemy et al., 2010). When EEST was administered to the animals, it was evident that life span of the EAC bearing mice was increased by restricting the activity of the EAC cells (Figure 2). In cancer, decrease in nutritional fluid volume and arresting the tumor growth may increase the life span of animal (Knopp et al., 2011), and similar effect was observed in EAC-bearing mice treated with EEST. The algae extract was successful in reducing the ascites fluid volume, viable cell count, and increased the percentage of life span, supporting its anticancer properties. Tryphan blue dye exclusion assay for in vitro cytotoxicity studies revealed that this algal extract is toxic to the EAC and percentage cell death was in concurrent with concentration of algal extract (Figure 4).

Disturbances of the carbohydrate metabolism are fairly common in patients with malignancy and hypoglycemia is a characteristic feature of all types of cancer (Lengyel et al., 2013). Uncontrolled gene expression leads to an increase in the protein concentration and with increase in the cell turn over, level of uric acid increases in EAC bearing mice. Liver being the immediate target organ affected by fast growing EAC cells (Szabados et al., 1989), leads to an alteration in the lipid profile. These biochemical events are known to be altered in EAC bearing cells (Gupta et al., 2004) and were observed in the disease control animals (group-2). Animals in the 
group 3-5 treated with EEST restored these biochemical parameters and evident of antitumor potential of the EEST on EAC cells (Figure 5).

Serum enzymes been used as possible early indicators of neoplasia and as aids in the progression and regression of cancer (Bodansky, 1973). Sometimes, cytotoxic agent itself or its toxic metabolite may cause hepatotoxicity, however in other instances they can be carcinogenic. In case of rapid cell destruction associated with extensive purine catabolism (Schwendel et al., 1994), urates as the metabolite from purine metabolism may precipitate in the renal tubules and may lead to complications in liver and kidney and damage of the organ (Weber, 1983; Fini et al., 2012). Hepatic enzymes (SGOT, SGPT and ALP) in EAC inoculated animals is known to be elevated (Salem et al.,2011) and similar observation was seen in this study with significant increase in the enzyme. By treating the animals with EEST, levels of these marker enzymes were remarkably reversed to normal level suggesting restoration of the function and integrity of liver (Figure 6).

Free radicals and its implication in tumor has been studied extensively (Feng et al., 2001; Ravid and Koren, 2003; Czeczot et al., 2010; Salem et al., 2011). Lipid peroxidation, an autocatalytic free radical chain propagation reaction is known to be associated with pathological condition of a cell (Czeczot et al., 2010). Increase in lipid peroxidations will lead to degeneration of tissues and lipid peroxide formed in the primary site is now transferred through circulation and provoke damage by propagating the process of lipid peroxidations (Kumar et al., 2003). As a cancer grows, its physical presence can affect nearby tissues and may affect functions of the vital organs, especially the liver. In carcinomatous tissue, malondialdehyde (MDA) which is the end product of lipid peroxidations is higher than in non-disease organs (Sinclair et al., 1990) and its level is interrelated with advanced clinical stages and the impairment is related to tumor progression (Ahmed et al., 1999). Additionally, because of high toxicity of MDA and inhibitory action on protective enzymes, MDA is claimed to act as a tumor promoter and co-carcinogenic agent (Seven et al., 1999). Decrease in SOD activity in EAC cells and the loss of mitochondria, leading to a decrease in total SOD activity in the liver of EAC bearing mice (Sun et al., 1989).

Glutathione, a potent inhibitor of neoplastic process play an important role as an endogenous antioxidant system that is found particularly in high concentration in liver and also is known to have key function in protective process (Rudin et al., 2003) and glutathione and catalase are also involved in the free radial scavenging activity (Ozkan and Fiskin, 2004). In disease control animals (group-2) reduction in the level of scavengers was observed as a result of tumor growth, where as treatment with EEST reversed the levels of these scavenges to normal level of LPO. Significant increase in the LPO levels in the liver of tumor bearing mice may relate to reduced activity of GSH. These above observation of antioxidant measures in the animals treated with EEST were comparable with the standard drug 5-FU (Figure 7).

Antitumor activity of $S$.tenerrimum is to be an adjunct to the increase of antioxidant property. The extract also restored the hepatic lipid peroxidation and free radical scavenging GSH as well as antioxidant enzymes in tumor-bearing mice to approximately normal levels. Plant and algal derived extracts containing antioxidant principles is known to be cytotoxic towards tumor cells (Li and Oberley, 1997). The free radical hypothesis supported the fact that the antioxidant potential of $S$. tenerrimum effectively inhibited the tumor growth and the observations of anticancer activity may be correlated with the antitumor and antioxidant principles present in the extract. Further studies will be focused on the isolation of the active principles responsible for the antitumor potential of S. tenerrimum.

In conclusion, EEST possessed significant anticancer and antioxidant activity due to the presence of alkaloids, terpenoids and flavonoids. Further investigation to evaluate the active ingredients and understating the mechanism of action will provide new scope of use of marine organism as a potent source of anticancer drugs. .

\section{Acknowledgements}

The Algae alga was taxonomically identified and was authenticated by an algologist Prof. Sridharan DJ, Division of Botany, National College, Trichy.

\section{References}

Ahmed MI, Fayed ST, Hossein H, et al (1999). Lipid peroxidation and antioxidant status in human cervical carcinoma. Dis Markers, 15, 283-91.

Ali R, Mirza Z, Ashraf GM, et al (2012). New anticancer agents: recent developments in tumor therapy. Anticancer Res, 32, 2999-3005.

Bodansky O (1973). Biochemical tests for cancer. CA Cancer J Clin, 23, 275-80.

Brown TD, Burris HA, Havlin KA, et al (1991). New anticancer agents. Cancer Chemother Biol Response Modif, 12, 111-46.

Burney IA, Furrukh M, Al-Moundhri MS (2014). What are our Options in the Fight against Breast Cancer? Sultan Qaboos Univ Med J, 14, 149-51.

Calixto-Campos C, Zarpelon AC, Correa M, et al (2013). The Ehrlich tumor induces pain-like behavior in mice: a novel model of cancer pain for pathophysiological studies and pharmacological screening. Biomed Res Int, 2013, 624815.

Chen X, Nie W, Yu G, et al (2012). Antitumor and immunomodulatory activity of polysaccharides from Sargassum fusiforme. Food Chem Toxicol, 50, 695-700.

Czeczot H, Scibior-Bentkowska D, Skrzycki M, et al (2010). [Lipid peroxidation level in gastrointestinal tract tumors]. Pol Merkur Lekarski, 29, 309-14.

Desbois AP (2014). How might we increase success in marinebased drug discovery? Expert Opin Drug Discov, 1-6.

Dolai N, Karmakar I, Suresh Kumar RB, et al (2012). Evaluation of antitumor activity and in vivo antioxidant status of Anthocephalus cadamba on Ehrlich ascites carcinoma treated mice. J Ethnopharmacol, 142, 865-70.

Dolma S, Lessnick SL, Hahn WC, et al (2003). Identification of genotype-selective antitumor agents using synthetic lethal chemical screening in engineered human tumor cells. Cancer Cell, 3, 285-96.

El-Shemy HA, Aboul-Soud MA, Nassr-Allah AA, et al (2010). Antitumor properties and modulation of antioxidant enzymes' activity by Aloe vera leaf active principles isolated 
via supercritical carbon dioxide extraction. Curr Med Chem, 17, 129-38.

Feng Q, Kumagai T, Torii Y, et al (2001). Anticarcinogenic antioxidants as inhibitors against intracellular oxidative stress. Free Radic Res, 35, 779-88.

Fini MA, Elias A, Johnson RJ, et al (2012). Contribution of uric acid to cancer risk, recurrence, and mortality. Clin Transl Med, $1,16$.

Gothoskar SV, Ranadive KJ (1971). Anticancer screening of SAN-AB: an extract of marking nut, Semecarpus anacardium. Indian J Exp Biol, 9, 372-5.

Goto T, Tomizawa N, Kobayashi E, et al (2004). A comparative pharmacology study between the intracolonic and oral routes of 5-FU administration in a colon cancer-bearing Yoshida sarcoma rat model. J Pharmacol Sci, 95, 163-73.

Gupta M, Mazumder UK, Kumar RS, et al (2004). Antitumor activity and antioxidant status of Caesalpinia bonducella against Ehrlich ascites carcinoma in Swiss albino mice. $J$ Pharmacol Sci, 94, 177-84.

Haldar PK, Kar B, Bala A, et al (2010). Antitumor activity of Sansevieria roxburghiana rhizome against Ehrlich ascites carcinoma in mice. Pharm Biol, 48, 1337-43.

Jung H, Choi SC (1994). Sequential method of estimating the LD50 using a modified up-and-down rule.J Biopharm Stat, 4, 19-30.

Khan SS, Nazim K, Mehmood KT, et al (2012). Phytochemical and antibacteria screening of crude extract of Sargassum tenerrimum J. Agardh against potential human pathogens. FUUAST Journal of Biology, 2, 65-8.

Khanavi M, Nabavi M, Sadati N, et al (2010). Cytotoxic activity of some marine brown algae against cancer cell lines. Biol Res, $43,31-7$.

Knopp KL, Nisenbaum ES, Arneric SP (2011). Evolving cancer pain treatments: rational approaches to improve the quality of life for cancer patients. Curr Pharm Biotechnol, 12, 1627-43.

Kumar MS, Unnikrishnan MK, Patra S, et al (2003). Naringin and naringenin inhibit nitrite-induced methemoglobin formation. Pharmazie, 58, 564-6.

Lee KH (1999). Anticancer drug design based on plant-derived natural products. $J$ Biomed $S c i, 6,236-50$.

Lengyel Z, Boer K, Halaszlaki C, et al (2013). [Diabetes in patients with malignant tumors]. Magy Onkol, 57, 177-81.

Li JJ, Oberley LW (1997). Overexpression of manganesecontaining superoxide dismutase confers resistance to the cytotoxicity of tumor necrosis factor alpha and/or hyperthermia. Cancer Res, 57, 1991-8.

Lu C, Lee JJ, Komaki R, et al (2010). Chemoradiotherapy with or without AE-941 in stage III non-small cell lung cancer: a randomized phase III trial. J Natl Cancer Inst, 102, 859-65.

Miranda JJ, Kinra S, Casas JP, et al (2008). Non-communicable diseases in low- and middle-income countries: context, determinants and health policy. Trop Med Int Health, 13, 1225-34.

Misra HP, Fridovich I (1972). The role of superoxide anion in the autoxidation of epinephrine and a simple assay for superoxide dismutase. J Biol Chem, 247, 3170-5.

Mohun AF, Cook IJ (1957). Simple methods for measuring serum levels of the glutamic-oxalacetic and glutamic-pyruvic transaminases in routine laboratories. J Clin Pathol, 10, 394-9.

Moron MS, Depierre JW, Mannervik B (1979). Levels of glutathione, glutathione reductase and glutathione S-transferase activities in rat lung and liver. Biochim Biophys Acta, 582, 67-78.

Ohkawa H, Ohishi N, Yagi K (1979). Assay for lipid peroxides in animal tissues by thiobarbituric acid reaction. Anal Biochem, 95, 351-8.
Ozkan A, Fiskin K (2004). Epirubicin $\mathrm{HCl}$ toxicity in humanliver derived hepatoma G2 cells. Pol J Pharmacol, 56, 435-44.

Patra S, Muthuraman MS (2013). Gracilaria edulis extract induces apoptosis and inhibits tumor in Ehrlich ascites tumor cells in vivo. BMC Complement Altern Med, 13, 331 .

Ravid A, Koren R (2003). The role of reactive oxygen species in the anticancer activity of vitamin D. Recent Results Cancer Res, 164, 357-67.

Riely GJ, Gadgeel S, Rothman I, et al (2007). A phase 2 study of TZT-1027, administered weekly to patients with advanced non-small cell lung cancer following treatment with platinum-based chemotherapy. Lung Cancer, 55, 181-5.

Rudin CM, Yang Z, Schumaker LM, et al (2003). Inhibition of glutathione synthesis reverses Bcl-2-mediated cisplatin resistance. Cancer Res, $\mathbf{6 3}, 312-8$.

Salem FS, Badr MO, Neamat-Allah AN (2011). Biochemical and pathological studies on the effects of levamisole and chlorambucil on Ehrlich ascites carcinoma-bearing mice. Vet Ital, 47, 89-95.

Schwendel A, Siems WG, Grune T, et al (1994). Transitions of hepatic purine metabolism of Ehrlich ascites tumor bearing mice in different phases of tumor growth. Biochem Mol Biol Int, 34, 457-63.

Seven A, Civelek S, Inci E, et al (1999). Evaluation of oxidative stress parameters in blood of patients with laryngeal carcinoma. Clin Biochem, 32, 369-73.

Sharma OP 1986. Textbook of Algae, New Delhi, Tata McGrawHill Education.

Simmons TL, Andrianasolo E, McPhail K, et al (2005). Marine natural products as anticancer drugs. Mol Cancer Ther, $\mathbf{4}$, 333-42.

Sinclair AJ, Barnett AH, Lunec J (1990). Free radicals and antioxidant systems in health and disease. Br J Hosp Med, $43,334-44$.

Singaravelu G, Arockiamary JS, Kumar VG, et al (2007). A novel extracellular synthesis of monodisperse gold nanoparticles using marine alga, Sargassum wightii Greville. Colloids Surf B Biointerfaces, 57, 97-101.

Sinha AK (1972). Colorimetric assay of catalase. Anal Biochem, 47, 389-94.

Sun Y, Oberley LW, Elwell JH, et al (1989). Antioxidant enzyme activities in normal and transformed mouse liver cells. Int $J$ Cancer, 44, 1028-33.

Sur P, Ganguly DK (1994). Tea plant root extract (TRE) as an antineoplastic agent. Planta Med, 60, 106-9.

Szabados G, Tretter L, Horvath I (1989). Lipid peroxidation in liver and Ehrlich ascites cell mitochondria. Free Radic Res Commun, 7, 161-70.

Tohme R, Darwiche N, Gali-Muhtasib H (2011). A journey under the sea: the quest for marine anti-cancer alkaloids. Molecules, 16, 9665-96.

Weber G (1983). Enzymes of purine metabolism in cancer. Clin Biochem, 16, 57-63.

Ye H, Wang K, Zhou C, et al (2008). Purification, antitumor and antioxidant activities in vitro of polysaccharides from the brown seaweed Sargassum pallidum. Food Chemistry, 111, 428-32.

Yende SR, Harle UN, Chaugule BB (2014). Therapeutic potential and health benefits of species. Pharmacogn Rev, 8, 1-7.

Zandi K, Ahmadzadeh S, Tajbakhsh S, et al (2010). Anticancer activity of Sargassum oligocystum water extract against human cancer cell lines. Eur Rev Med Pharmacol Sci, 14, 669-73. 